This is an electronic reprint of the original article. This reprint may differ from the original in pagination and typographic detail.

Author(s): Hämäläinen, Raija; Oksanen, Kimmo

Title: $\quad$ Challenge of supporting vocational learning: Empowering collaboration in a scripted 3D game - How does teachers' real-time orchestration make a difference?

Year: $\quad 2012$

Version:

Please cite the original version:

Hämäläinen, R., \& Oksanen, K. (2012). Challenge of supporting vocational learning: Empowering collaboration in a scripted 3D game - How does teachers' real-time orchestration make a difference?. Computers \& Education, 59(2), 281-293. https://doi.org/10.1016/j.compedu.2012.01.002

All material supplied via JYX is protected by copyright and other intellectual property rights, and duplication or sale of all or part of any of the repository collections is not permitted, except that material may be duplicated by you for your research use or educational purposes in electronic or print form. You must obtain permission for any other use. Electronic or print copies may not be offered, whether for sale or otherwise to anyone who is not an authorised user. 


\title{
Challenge of supporting vocational learning: Empowering collaboration in a scripted 3D game - How does teachers' real-time orchestration make a difference?
}

\author{
Postprint version of \\ Hämäläinen, R. \& Oksanen, K. (2012). Challenge Of Supporting Vocational Learning: Empowering \\ Collaboration In A Scripted 3D Game - How Does Teachers' Real-Time Orchestration Make A Difference? \\ Computers \& Education, 59(2), (281-293). http://dx.doi.org/10.1016/j.compedu.2012.01.002
}

\author{
Raija Hämäläinen* \& Kimmo Oksanen \\ Finnish Institute for Educational Research \\ Keskussairaalantie 2, P.O. Box 35, FI-40014 University of Jyväskylä \\ Tel +358407442611 \\ Fax +35814617418 \\ raija.h.hamalainen@jyu.fi
}

\begin{abstract}
Along with the development of new technologies, orchestrating computer-supported collaborative learning (CSCL) has become a topic of discussion because new learning spaces challenge teacher to support collaborative learning in new ways. However, despite the optimistic notions of teachers' orchestration in CSCL situations, there are still no systematic research findings on real-time orchestration. This study is one attempt to fill in the knowledge gap on understanding the differences in knowledge construction processes between settings with and without teachers' real time orchestration in 3D learning games from a socio-cultural perspective. The aims of the study are twofold. The first aim is to design a scripted 3D learning game to practice inter-professional knowledge construction in a vocational context. The second goal is to determine the main differences in knowledge construction processes in 3D game settings with and without real-time teacher orchestration. Findings provide new insights into what actually happens in collaboration processes within different learning settings. Specifically, students in settings with real-time teacher orchestration used more effort to provide knowledge (especially explaining one's own situation) and less effort for other inputs (in particular, off-task discussion). Thus, a scripted 3D game itself guided and helped groups to solve tasks. However, teachers' professional competencies also helped to reduce off-task discussions during the 3D game, develop a shared understanding of the tasks' inter-professional nature, and explain activities in a meaningful way.
\end{abstract}

Keywords: Orchestrating computer-supported collaborative learning (CSCL), design-based research, sociocultural approach, vocational learning, 3D learning game

\section{Introduction}

The changing needs of working life and society create new challenges for both learning and teaching in educational settings. Work tasks have become increasingly complicated and work is typically based on interprofessional expertise and the shared construction of new knowledge (Billett 2008). Typically in vocational school settings, however, students of different fields do not work together to solve problems. As vocational jobs are likely to call for collaboration in the future, it is necessary to find new ways of supporting collaboration in vocational learning. One way to respond to these needs is to create new technology-enhanced learning (TEL) spaces that offer an added incentive to practice inter-professional collaboration. During the past several years, TEL environments have rapidly improved through the development of social media, 3D spaces (e.g. Second Life), and games for learning. Thus, technology can be utilized to enhance collaboration in learning (see Wang, 2009) and working practices, for example, by offering more illustrative spaces to practice inter-professional work, thus eliminating the danger in work safety compared to traditional methods (Hämäläinen, Oksanen \& Häkkinen 2008). Despite these optimistic notions of new TEL spaces meeting the needs of inter-professional working life, there is a paucity of systematic empirical CSCL research on learning in vocational contexts such as higher educational settings.

Several researchers have written about the benefits of CSCL (e.g. De Wever et al. 2010), and many agree that collaborative CSCL has potential, based on the notion that joint construction of shared understanding, meaning knowledge and expertise will enable groups to create more than one individual could achieve (Stahl 2004). In practice, "ideal" high-level collaboration is nevertheless rare, and there are challenges to creating it in technology-enhanced school settings. (Kollar 2010; Hämäläinen 2011). These challenges often resolve to problems in collaborative group work (Järvelä, Volet \& Järvenoja 2010). Moreover, recent studies have pointed 
to certain reasons for these failures, such as unevenly divided work tasks (Strijbos \& De Laat 2010), the poor working methods of individual group members (e.g. problems in argumentation) (Hämäläinen \& Häkkinen 2010; Kollar, Fischer \& Slotta 2007), problems in skills to regulate learning (Järvelä \& Järvenoja 2011), fragile group dynamics (Kreijins, Kirschner, Jochems \& Buuren 2007), weak teamwork strategies (Hadwin \& Järvelä, 2011), the inappropriate use of learning resources (Arvaja 2007; Jeong \& Hmelo-Silver 2010) or the lack teachers to inspire and orchestrate learning processes (Arvaja, Hämäläinen \& Rasku-Puttonen 2009). Thus, although technology has rapidly advanced, the challenges of collaborative learning remain. Particularly in authentic learning contexts (with changing circumstances), totally free collaboration does not necessarily promote productive collaboration or high-level learning. Previous research has focused on collaboration scripts as a particular kind of instructional approach to support CSCL. The main idea of collaboration scripts is to improve collaboration through structuring interaction processes (e.g. to solve socio-cognitive conflicts) among learners (for a detailed description of collaboration scripts see Kobbe, Weinberger, Dillenbourg, Harrer, Hämäläinen, Häkkinen et al. 2007). However previous studies on collaboration scripts have typically been conducted without the teacher's real-time support. Recent critical studies have suggested that focusing only on specific scripts reduces - or even negates - the role of teachers in supporting collaboration (Dillenbourg \& Jermann 2010). In addition, Lund and Smørdal (2006) have argued that there is a lack of studies that address the teacher's role in understanding and fostering group processes. Therefore, along with the development of scripts, it is necessary to pay attention to the effective and flexible use of the potential offered by future learning spaces in which teachers play an active role.

In recent research, flexible orchestration has been viewed as a solution to arranging collaboration in naturalistic learning situations (e.g. Dillenbourg, Järvelä \& Fischer 2009; Kollar 2010). The concept itself is not new (Brown 1992; Meyer \& Watson, 1991) but has received increased attention through the paradigmatic changes in applying new knowledge, technology, and the changing needs of society. The newly created learning environments (e.g. 3D spaces) challenge teachers to support collaborative learning in new ways. In orchestrating CSCL, the aim is to maintain balance between the instructions, "free collaboration processes," and the contextual nature of collaboration, whereas the features of design and real-time implementation of teaching draw systematically on research-based, productive, collaborative learning situations (Kollar, Hämäläinen, Evans, De Wever \& Perrotta 2011). The aim, in short, is to combine design and improvisation. In detail, the teacher designs and orchestrates the structure for the learning processes (based on research findings) while the activities rest on the curriculum and the scripted environment supports collaboration. The learners, for one, are given enough degrees of freedom to construct shared knowledge. The collaborative learning situation thus challenges the teacher to simultaneously design, monitor, and support the group learning processes based on situational needs (Hämäläinen \& Vähäsantanen 2011). This study supplements research on collaboration scripts by teachers and timely support, and focuses on flexible approaches to orchestrate learning in future TEL spaces (e.g. Dillenbourg et al. 2009). To date, there are no systematic research findings indicating whether orchestration is actually needed in scripted $3 \mathrm{D}$ game settings. Therefore, the main interest of this empirical study is to explore the role of real-time teachers' orchestration in knowledge construction processes that takes place in vocational learning settings.

The core of this study is design-based research (e.g., Barab \& Squire 2004; Wang \& Hannafin 2005), which attempts to combine technological development, the needs of authentic vocational learning, and theoretical knowledge of collaborative learning as a basis for enhancing high-level knowledge construction. This empirical study continues the design-based research project (see Brown 1992; Design-Based Research Collective 2003) focusing on designing and investigating theoretically-constructed 3D learning games based on the authentic vocational education needs (ongoing since 2004). The aims of the study are thus twofold: first, to develop a 3D game, and second, to identify what the main differences are in knowledge construction processes between the settings with and without real-time teacher orchestration. To explore this issue, we compare knowledge construction processes between settings using scripted 3D learning games with (condition 1) or without (condition 2) real-time teacher support. In line with this, we also address the challenge of investigating collaborative knowledge construction. Against this background, we will next describe the theoretically constructed 3D game, and then move to describe our study's methodological background. Finally, we will conclude by discussing the main differences in knowledge construction processes between the settings with and without real-time teacher orchestration.

\section{Scripted 3D learning game}

In this study, a 3D online learning game for groups of five participants at a time with scripted tasks (see Kobbe et al. 2007) was developed. The 3D online learning game is based on the notion that future work-life is based on inter-professional expertise and the shared construction of new knowledge, and there is a need to improve communication to reach a shared understanding, processes, and work principles in interagency-work (Billett 
2008; Collin, Paloniemi \& Mecklin 2010). Thus, the aim of the scripted 3D game is to enhance the interprofessional knowledge construction in the area of human sustainability. Specifically, in our 3D game, participants work as volunteer staff at a charity concert; they must prepare for the event and ensure that customers are satisfied. To achieve this, participants solve inter-professional puzzles. The game includes three main puzzles. The first puzzle (Gate; aiming for coordination) creates dependency between group members (Brown \& Campione 1994; Barron 2000). In practice, groups need to open a gate to the festival area by correctly entering a password into the electronic lock. In the second puzzle (Restaurant; aiming for distributed expertise, mutual dependency, and integration of solo - group activities), dependency between participants is created by distributing different knowledge and resources to each of the learners (Price et al. 2003), leading to personal responsibility, shared knowledge construction, and the need to combine different professions. In practice, groups are expected to keep customers satisfied by serving them in the restaurant area. Students have supplementary inter-professional roles. The roles are: cook, waitress, receptionist, and serviceman. Every student has his/her own responsibility area and students are supposed to integrate and synchronize those tasks together. At the end of the task, band members come to the restaurant to have lunch. One band member has a nut allergy, but he still wants to have a portion that usually includes nuts. The group needs to identify the allergy and serve the right portion without nuts to the singer. In the final puzzle (Stage; aiming for solving sociocognitive conflict), a collaboration situation is created by having various learners receive different information at the same time, but without proper coordination, causing an unsolvable problem (Moscovici \& Doise 1994; Cress \& Kimmerle 2008). Thus, the group's task is to identify each band member by combining received tips. Each student receives his/her own tips, and players need to recognize who is who in terms of the band members. In this way, players are able to organize the band's equipment in the right place on the stage.

The learning game is based on RealXtend Technology (Open Source Platform for interconnected virtual worlds http://www.realxtend.org/) (see Figure 1). The environment provides each participant with a first-person view into the 3D game. Participants are connected to each other via a server, which runs the virtual world in which all the action occurs. The game can be accessed with a PC that has a network connection, and human-to-human communication is supported by the VoIP speech system.

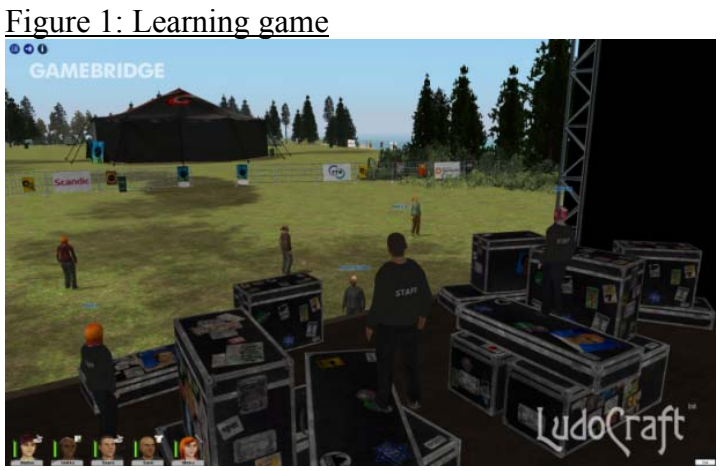

\section{Material and methods}

Technology is often seen as an organizational means for generating traditional learning. In contrast to this view, the present study examines design-based research that allows for a full articulation of the role of technology as a mediating tool for intellectual and social development (Ravenscroft, Sagar, Baur \& Oriogun. 2008). The central goal in the study is to integrate empirical research on learning and teaching with particular designs for instruction (Hoadley 2004). In practice, the study integrates the design of a theoretically grounded 3D game with empirical research (see research aims). Furthermore, the aim is to improve real-life educational practices through the design, development, analysis, and implementation of innovative technological interventions. This requires active collaboration on behalf of researchers and practitioners who aim to solve problems in educational practices (Oh \& Reevers, 2010; Wang \& Hannafin 2005).

The pragmatically oriented aim of this study was to enhance inter-professional expertise in the vocational worklife context by relevant new means inapplicable to traditional classroom settings. Thus, grounded in the theory of CSCL and the authentic needs of vocational education, the 3D game environment was designed in iterative collaboration with teachers and work-life instructors $(\mathrm{N}=8)$, and a game company. Moreover, the study follows the iterative structure of design-based research in the sense that the improvements made on previous 
interventions interact with the design of the 3D environment. (In each intervention, a new 3D environment was designed and tested.) Furthermore, our methods of data collection and analysis build on recent theoretical knowledge. In practice, we have employed an experimental design that combines aspects of theoretical knowledge of collaboration processes (see the game description), developing methods of investigating knowledge construction, empirical findings of our previous studies, and continuous development of the technological environment. In this general framework, findings of earlier sub-studies have been reported as individual case studies (see Hämäläinen 2008, 2011; Hämäläinen et al., 2008).

The aim of design-based research is to generate and instantiate empirically-grounded theoretical knowledge and identify new principles that can serve as a foundation for creating future TEL practices (Oh \& Reevers 2010). Thus, while our previous design-based studies involved only analysis of student groups' collaboration in 3D game settings, this study investigates the differences in knowledge construction processes in groups working with and without real-time teacher orchestration. The CSCL research society has yielded several optimistic notions on real-time orchestration although empirical findings on the topic are still to come. As for the analysis, a mixed method approach of qualitative and quantitative content analysis was applied in this study (Clark, Creswell, Green \& Shope, 2008) for which quantitative measures of qualitative data were created (Hesse-Biber, 2010).

\subsection{Grounding points}

In the following sections, we will first describe how our previous research grounds this study in two principal ways. Secondly, we will discuss the role of the teacher in this empirical experiment. After these, we will open the context and data analysis of the study.

First, the methodology used in this study is based on our earlier work. We will further develop analysis of collaborative knowledge construction as a means of gaining insight into the process of collaborative learning in a scripted 3D environment from a socio-cultural perspective. Added to this, our previous study (Hämäläinen et al. 2008) has indicated that faster groups do better in their final test results than the slower groups, and higher learning results seem to be bound to high knowledge construction processes. Therefore, we compared the time used in the task solving with and without teacher orchestrating collaboration activities. However, within this environment, the main goal of collaboration activity was not to increase individual learning outcomes in a specific context (in contrast to the previous study), and therefore we did not evaluate the learning outcomes. In this study, the main goal was to enhance collaborative understanding of inter-professional challenges of work life in a vocational context.

Second, different kinds of collaboration scripts with theoretically-grounded design principles (e.g. arranging socio-cognitive conflicts) have been used successfully to foster specific interactions in 3D games environments. However, our previous studies have been conducted without real-time teacher support. Recent critical studies have suggested that focusing only on specific scripts reduces - or even negates - the role of teachers in supporting collaboration (Dillenbourg \& Jermann 2010). Furthermore, Collazos and colleagues (2007) have stressed that it is important not only to design the environments to support knowledge construction, but also to consider whether the teacher's participation influences knowledge construction processes in these environments. Therefore, this study emphasizes the role of real-time teachers' orchestration in knowledge construction processes, and more specifically, what the main differences are in knowledge construction processes between the settings with and without real-time teacher orchestration. This empirical study attempts to answer the critique that technology alone cannot replace the teacher in supporting creative collaboration processes (Littleton 2009). To conclude, we aim to supplement our previous approach by teachers' timely support in scripted 3D learning game.

This study combines socio-cultural approaches and instructional design (Dillenbourg \& Tchounikine 2007), emphasizing group learning and the social context in which collaboration emerges to highlight the role of shared knowledge construction (Stahl 2006; Tchounikine 2008). The study is based on the approach that creative shared knowledge construction processes take place in the collaboration between people and are intertwined with the present technological environment (see Glăveanu 2010). The main idea is that group learning emerges in contextual interaction processes by members of the group distributing their own thoughts and expertise, by listening to and elaborating on the others' views, and by the creative and shared knowledge construction of different thoughts and conclusions to reach common goals (Crook 1998; Lund \& Rasmussen 2008; Roschelle \& Teasley 1995; Sawyer 2007). The role of the teacher is in line with the Vygotskyan notion of facilitating learning through joint knowledge construction in which the teacher and students work together on a common 
product and goal (see Tharp, Estrada, Dalton \& Yamauchi 2000). Thus, the teacher is seen as an important fellow contributor in productive collaboration processes (Mercer, Hennessy \& Warwick 2010). In this study, a particular focus is on enhancing the emergence of collaboration with the mediating role of scripted 3D game and investigating if a teacher's role in shared knowledge construction is beneficial (Hämäläinen \& Vähäsantanen 2011; Wells \& Claxton 2002). To sum up, our approach highlights collaboration as a creative and situated interaction process mediated by the present technological environment (John-Steiner 2000; Miell \& Littleton 2004; Sawyer \& DeZutter 2009; Wegerif 2007).

\subsection{Participants, context, and data collection}

The empirical study was conducted in an authentic classroom (additionally, one video camera and recording system were used in each setting) to capture all the required data from the collaboration situations. The video camera was positioned to capture video feed from a virtual camera (observers' view) through one non-player display (inside the 3D environment, handled by one of the researchers). In fall of 2010, 18 (16 to 18-year-old) vocational students and two teachers (four groups of five persons) participated in the study (names are pseudonyms) ( $\mathrm{N}=20$, all males) (see Figure 2). The students were randomly divided into four groups, but the teachers were intentionally placed in different groups to form varied working conditions. The empirical study included a two-to-three hour working period in a scripted 3D learning game at the College of Jyväskylä, Finland. In order to avoid compromising the research setting, the participants were physically isolated from one another. Cubicles were arranged in a way that the participants were not disturbed from outside the 3D world and could only communicate through the VoIP speech system. No specific instructions were given to participants before the working period. Then, two groups with (condition $1=$ setting 1 ) and two groups without (condition 2 $=$ setting 2) real-time teacher orchestration solved scripted puzzles in a 3D learning game. Data were gathered using observational notes on the sessions, as well as by videotaping and recording the groups' discussions (6016 transcribed utterances). Groups' discussions were recorded straight from the VoIP speech system using software "Audacity."

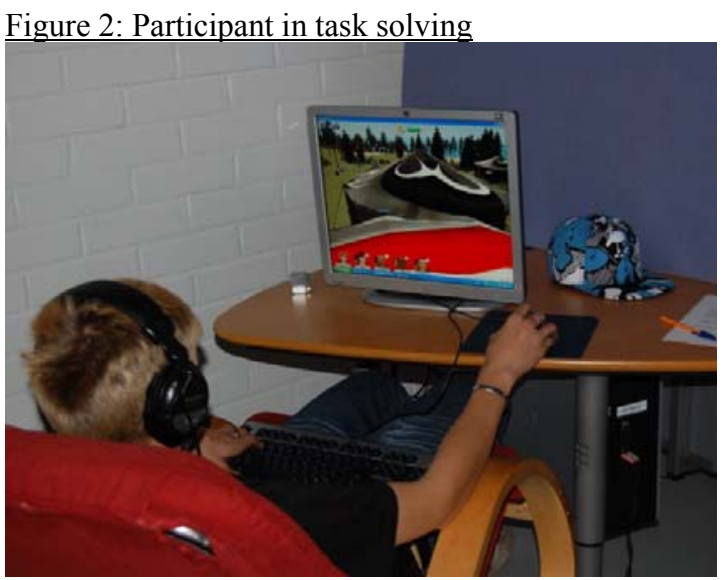

\subsection{Data analysis}

In CSCL, research collaboration is typically interpreted and investigated from two different perspectives, i.e., individual and group learning. Educational psychology-oriented research typically focuses on how effective various collaboration interventions are for individual learners and socio-cultural research-oriented research focuses on group learning and the social context (Dillenbourg 2006). Thus, both perspectives can be criticized as focusing too much on groups' own collaboration activities or learning outcomes without investigating the role and effects of teachers' support for collaboration processes (e.g. the focus of design-based research has typically been on developing learning environments that would rather replace the teacher than move him/her to the center, Kollar et al. 2011). This study is one attempt to fill in this knowledge gap; our approach is in line with De Wever and others (2006) who highlight the importance of shared knowledge construction in the analysis of collaborative learning. The analysis is based on the interpretation of Arvaja, Salovaara, Häkkinen and Järvelä (2007), according to whom collaboration is defined as a shared knowledge construction in which participants' cumulative sharing of knowledge is not sufficient (Mercer 1996), but the knowledge construction needs to be built on others' ideas and thoughts. Added to this, knowledge and understanding have to be jointly created (Mercer 2011). Therefore, we investigate collaboration based on shared learning processes and/or activities. To understand these, we apply quantitative and qualitative content analyses (Berelson 1952). 
According to Bouta, Retalis and Paraskeva (2012) combining quantitative and qualitative data brings together the strengths of both forms of research in 3D contexts. Thus, the aim of the analysis is not only to evaluate the quality of collaboration based on individual messages, but in addition, to seek what goes on between participants' interactions (Arvaja 2007). Next, we present four phases of the data analysis: (1) revising the data, (2) comparing the time used, (3) analyzing collaboration with content analysis, and (4) comparing the differences between the learning settings.

Revising the data: After the empirical study, all video data were transcribed and discussion entries were read through several times. Then, all of the data were verified: videos were watched, observations were rechecked, and transcribed utterances were re-examined (at this stage, 5386 of 6016 utterances were categorized to include activities of shared knowledge-construction). Examples of excluded utterances were unclear overlapping speech acts, laughing, and an individual's own soliloquy that was unrelated to shared knowledge construction with others.

Comparing the time used: As our earlier studies (Hämäläinen et al. 2008) have indicated that faster groups do better in their final test results and seem to have more high-level knowledge construction activities than the slower groups, we compared the time used to solve tasks with and without teacher orchestrating collaboration activities. The analysis next focused on shared knowledge construction processes within different learning settings.

Analyzing collaboration with content analysis: Content analysis has typically been applied from two different research perspectives (see Mercer 2010). At the early stage, collaborative discussions have been studied by sorting individual messages into categories and investigating their relationship with learning outcomes (e.g. Howe \& Tolmie 1999). However, that approach has been criticized for forgetting reciprocal characters of collaborative knowledge construction as well as the situational nature of the activity (Arvaja 2007; Baker 2010). Therefore, micro-level methods have been further developed to capture, understand, and describe knowledge construction processes within groups (e.g. Arvaja 2007). Such methods have proven successful in providing new insights into what actually happens in collaboration processes. However, there are critical reasons that methods need to be further developed. At the current stage, previous studies have not focused on the teacher's role within collaborative knowledge construction processes. In addition, a very limited amount of discussion has typically been analyzed with micro-level methods. After reading the discussion through a number of times, 5386 utterances were categorized to include activities of shared knowledge construction. The analysis of shared knowledge construction is in line with the notion of Vosniadou, Ioannides, Dimitrakopoulou, and Papademetriou (2001), who argue that learning is greatly facilitated by interactions with peers and particularly with a teacher acting at the zone of proximal development (Vygotsky 1978). The analysis of knowledge construction was thus divided into two steps and focused on understanding collaborative learning by making sense of the groups' collaboration processes (Hmelo-Silver 2003). In addition, the analysis is in line with the notion of Arvaja (2007), that it is not possible to study collaboration independently of the social settings in which it occurs. We examined the differences in the discussion data across settings, and the categorizations were validated and crosschecked by two independent researchers.

To evaluate knowledge construction and how various collaboration settings differed, quantitative and qualitative content analyses were conducted (Berelson 1952). The aim of the quantitative analysis was to determine whether there is a difference between the settings with and without real time teacher orchestration, while the aim of qualitative content analysis was to understand the nature of their differences (see Table 1). An utterance, i.e., typically one turn of speech of transcribed data, was chosen as the unit for analysis (Chi 1997). For example, Anna: "Or should I now-again fill up the device there or what should be done..?" is one utterance (Main category - Contextual questions; subcategory - Specifying). However, when grammatical utterances did not constitute semantic units of knowledge construction (e.g. "Now I have the chicken curry, but it contains nuts. Do we serve it anyway?"), one speed turn was interpreted as one utterance (Contextual questions; reasoning), as the first part ("Now I have the chicken curry, but it contains nuts") included the contextualization of the question necessary for understanding the knowledge construction process. At this phase, discussions were categorized into six theory-based main categories (e.g., Berger \& Calabrese 1975). Thus, the focus was on exchanges between the group members. The main categories were based on functional roles of the participants' utterances (Vosniadou et al. 2001). Classification had a theoretical grounding in Vosniadou and others' (2001) work on teacher/student interactions and our previous studies in the analysis of collaboration in vocational 3D learning contexts. Thus, the interpretation of functional roles was contextually adapted as within this context. In this study, teachers did not have the traditional role of "knowledge recourse" for students; rather the role of the teacher was to empower knowledge construction processes within the group. In practice, first, 5,386 utterances were organized into six main categories: A) "providing knowledge," B) "contextual questions," C) "shared 
problem solving," D) “management of interaction," E) "summing up/discovering a solution," and F) "other inputs" (see Table 1 for detailed descriptions). The goal of creating these main categories was to create a holistic picture of knowledge construction activities in different learning settings. Another goal was to find indicators to illustrate the quality of knowledge construction processes.

Table 1: Main categories in the knowledge construction analysis.

\begin{tabular}{|l|l|}
\hline Main category & Description \\
\hline Providing knowledge & $\begin{array}{l}\text { Bringing in new knowledge related to learning contexts and / or task } \\
\text { solving (e.g. giving advice, explaining one's own situation, giving } \\
\text { opinions) }\end{array}$ \\
\hline Contextual questions & $\begin{array}{l}\text { Asking questions related to context (e.g. new openings, specifying and } \\
\text { reasoning in the form of questions) }\end{array}$ \\
\hline Shared problem solving & $\begin{array}{l}\text { Knowledge construction that relates to others' discussion (e.g. reasoning, } \\
\text { clarifying, specifying) }\end{array}$ \\
\hline Management of interaction & Developing strategies for future activities (e.g. planning upcoming work) \\
\hline $\begin{array}{l}\text { Summing up/discovering } \\
\text { solution }\end{array}$ & $\begin{array}{l}\text { Summarizing previous information, verifying understanding, discovering a } \\
\text { solution }\end{array}$ \\
\hline Other input & $\begin{array}{l}\text { Speech acts related or not related to task solving that are part of the } \\
\text { knowledge construction with others }\end{array}$ \\
\hline
\end{tabular}

At the second level of analysis, to find qualitative differences within the knowledge-construction processes, the utterances were sorted further into 25 different data-driven subcategories within the 6 main categories (e.g., Beers, Boshuizen, Kirschner \& Gisselaers 2007) according to more detailed functions of interaction: A) providing knowledge (piece of advice - contextual, piece of advice - technical, new information, explaining one's own situation, justifying an opinion, and not justifying an opinion), B) contextual questions (new openings, technical, specifying, reasoning, and opinions), C) shared problem solving (continues one's work, answers, disagrees/argues, and reasons), D) management of interaction (group organization, planning upcoming activity, organizational questions, and support), E) summing up/discovering solutions (based on group activities, one's own activities, and unknown reasons), and F) other input (related to task solving, describing technical problems, and off-task knowledge construction related to the environment) (see Table 2 for detailed descriptions and empirical examples to illustrate the meaning). These subcategories were developed to ascertain whether knowledge construction really was built on others' ideas and thoughts. Related to this, transcripts were coded independently by both authors of the paper. Cohen's k for inter-judge agreement was 0.97 . After discussion between the coders, a total of $98.6 \%$ of the coding could be agreed on. However, it has to be noted that high agreement is influenced by the fact that both of the coders were actively involved in developing the method of analysis.

Table 2: Data-driven subcategories in the knowledge construction analysis.

\begin{tabular}{|l|l|}
\hline Subcategories & Description (with empirical example to illustrate the meaning) \\
\hline Providing knowledge & $\begin{array}{l}\text { Advice for task solving - } \\
\text { Hurry up now to make that curry chicken. Come here! }\end{array}$ \\
\hline Piece of advice - contextual & Advice for technical issues - It is there in the top corner. \\
\hline Piece of advice - technical & $\begin{array}{l}\text { Brings in new information - } \\
\text { The singer wants to have another portion to comply with his order. }\end{array}$ \\
\hline $\begin{array}{l}\text { Explaining one's own } \\
\text { situation }\end{array}$ & $\begin{array}{l}\text { Explaining one's own situation } \\
\text { I'm stuck on the lawn. }\end{array}$ \\
\hline Justified opinion & Own opinion with reasoning - \\
\hline Non- justified opinion & $\begin{array}{l}\text { Own opinion without reasoning - } \\
\text { This is cool... }\end{array}$ \\
\hline Contextual questions & $\begin{array}{l}\text { Bringing in new information or giving suggestions in question form - } \\
\text { I wonder what is missing from that guy there? }\end{array}$ \\
\hline New openings & $\begin{array}{l}\text { Asking about technical issues - } \\
\text { Did you get anything written there? }\end{array}$ \\
\hline Technical & $\begin{array}{l}\text { Asking for specifying knowledge - } \\
\text { What did he order? }\end{array}$ \\
\hline Specifying & Reasoning about knowledge in question form - \\
\hline Reasoning &
\end{tabular}




\begin{tabular}{|c|c|}
\hline & But why would that other singer have so much stuff? \\
\hline Opinion & $\begin{array}{l}\text { Expressing an opinion in question form - } \\
\text { She might have blue eyes, aren't those a bit like that? }\end{array}$ \\
\hline \multicolumn{2}{|l|}{ Shared problem solving } \\
\hline Continues one's work & $\begin{array}{l}\text { Continues shared knowledge construction begun by other group members - } \\
\text { Yes, it must be one of those large boxes. }\end{array}$ \\
\hline Answers & $\begin{array}{l}\text { Answering a question or giving clarification - } \\
\text { Hmm...the rhythm guitarist's hairdo calls for some care. }\end{array}$ \\
\hline Disagrees / argues & $\begin{array}{l}\text { Expressing disagreement or argument - } \\
\text { No, rhythm guitarist can't have that much stuff; assign it to the warm-up } \\
\text { band. }\end{array}$ \\
\hline Reasoning & $\begin{array}{l}\text { Reasoning about knowledge or task solution - } \\
\text { Because there is a male singer and a female singer in the band. }\end{array}$ \\
\hline \multicolumn{2}{|l|}{ Management of interaction } \\
\hline Group organization & $\begin{array}{l}\text { Organizing group activities - } \\
\text { Er... If we all leave now. }\end{array}$ \\
\hline Planning upcoming activity & $\begin{array}{l}\text { Giving suggestions, advice, or clarification about an upcoming activity related } \\
\text { to group work - } \\
\text { Come here in two minutes... I'll do that quotation. }\end{array}$ \\
\hline Organizational questions & $\begin{array}{l}\text { Organizing group work in question form - } \\
\text { Mike, would you come and take part in this food job when I give you this } \\
\text { one's orders? }\end{array}$ \\
\hline Support & $\begin{array}{l}\text { Supporting shared knowledge construction / task solving - } \\
\text { Okay, good, we got a bit further in this game again, that's cool. }\end{array}$ \\
\hline \multicolumn{2}{|l|}{$\begin{array}{l}\text { Summing-up } \\
\text { / discover solutions }\end{array}$} \\
\hline Based on group activities & $\begin{array}{l}\text { Summarizing a previously discussed / discovering a solution based on group } \\
\text { activities - } \\
\text { It must be one of these big ones }\end{array}$ \\
\hline Based on one's own actions & $\begin{array}{l}\text { Summarizing a previously discussed / discovering a solution based on own } \\
\text { activities - } \\
\text { (I have) the wrong recipes. }\end{array}$ \\
\hline Based on unknown reason/s & $\begin{array}{l}\text { Summarizing a previously discussed / discovering a solution based on an } \\
\text { unknown reason - } \\
\text { There must be some numbers here. }\end{array}$ \\
\hline \multicolumn{2}{|l|}{ Other input } \\
\hline $\begin{array}{l}\text { Other input - related to task } \\
\text { solving }\end{array}$ & $\begin{array}{l}\text { Other speech activity related to shared knowledge construction and task } \\
\text { solving - } \\
\text { Oh my God! }\end{array}$ \\
\hline Describing technical problems & $\begin{array}{l}\text { Describing technical problems of the 3D environment - } \\
\text { This speech echoes. }\end{array}$ \\
\hline $\begin{array}{l}\text { Off task - not related to } \\
\text { environment }\end{array}$ & $\begin{array}{l}\text { Other speech activity related to shared knowledge construction, but not } \\
\text { related to task solving - } \\
\text { Actually, I know a band that has three bassists. }\end{array}$ \\
\hline
\end{tabular}

To address the central research questions, the last phase of the analysis included comparing the differences between the learning settings in terms of time used and knowledge construction processes. The future target is to use that knowledge as a guideline for creating future learning scenarios related to teachers' orchestration of shared knowledge construction processes. The hope is that, in the future, they can be used as a resource in various TEL settings.

\section{Results}

At the general level, content analysis revealed that, in the scripted 3D game in the setting with teacher real-time orchestration, knowledge construction mainly involved providing knowledge, shared problem solving, and asking contextual questions (see Table 3). This finding is in line with our previous (design-based research) 
findings that, at their best, scripted 3D games have the potential to support knowledge construction in vocational educational settings (Hämäläinen 2008, 2011; Hämäläinen et al. 2008). However, unlike in our previous studies, comparing the differences between studying with and without real-time teacher orchestration resulted in differences in both time used on task solving and shared knowledge construction processes. Specifically, in the orchestrated learning setting, the learning session lasted an average of approximately 1 hour 58 minutes, while in the setting without orchestration, the session lasted an average of 2 hours 31 minutes.

\subsection{Main differences in knowledge construction}

Between the conditions involving studying with (2405 utterances) and without (2981 utterances) a real-time teacher's orchestration, the findings indicated two main differences in knowledge construction activities in the categories "providing knowledge" and "other input" (see Table 3). With respect to discussions, we see that the amount of "providing knowledge" was much higher in the setting with teachers" real-time orchestration $(41.7 \%$ of utterances) than in the setting without real-time orchestration ( $24 \%$ of utterances). Data-driven analysis indicated differences at a more specific level. As can be seen in Table 3 within the main type of discussion, "providing knowledge," there were no significant differences in how members brought in new information $(\mathrm{A}=15.8 \%, \mathrm{~B}=11.1 \%)$, gave technical $(\mathrm{A}=0.2 \%, \mathrm{~B}=0.4 \%)$ and contextual $(\mathrm{A}=6.7 \%, \mathrm{~B}=5.4 \%)$ advice to other members, and stated their (non-justified) opinions $(\mathrm{A}=1.2 \%, \mathrm{~B}=1.5 \%)$ in a scripted environment. Added to this, neither setting used justified opinions. The main difference in the discussions concerned the understanding of the task's inter-professional nature and the meaning of explaining one's own activities as a part of solving such tasks. The participants in setting with teachers' real-time orchestration (A) used 18 percent of their utterances to explain their own situation, while the participants setting without teacher orchestration (B) only used 5.9 percent of their utterances for this (see Table 3). Thus, in the setting with real-time teacher orchestration, explaining one's own activities was used more actively to develop shared knowledge and solve the scripted tasks than in the setting without real-time teacher orchestration.

Table 3: Main differences between the settings with and without real-time teacher orchestration.

\begin{tabular}{|c|c|c|c|c|c|c|}
\hline \multirow[b]{2}{*}{ Providing knowledge } & \multicolumn{3}{|c|}{$\begin{array}{l}\text { Setting } \mathrm{A}=\text { Groups with teacher } \\
\text { real-time orchestration }\end{array}$} & \multicolumn{3}{|c|}{$\begin{array}{l}\text { Setting B = Groups without teacher } \\
\text { real-time orchestration }\end{array}$} \\
\hline & 1003 & $41.7 \%$ & & 726 & $24 \%$ & $\%$ \\
\hline Piece of advice - contextual & 162 & & $6.7 \%$ & 161 & & $5.4 \%$ \\
\hline Piece of advice - technical & 5 & & $0.2 \%$ & 11 & & $0.4 \%$ \\
\hline New information & 380 & & $15.8 \%$ & 332 & & $11.1 \%$ \\
\hline Explaining one's own situation & 428 & & $18 \%$ & 177 & & $5.9 \%$ \\
\hline Justified opinion & 0 & & $0 \%$ & 0 & & $0 \%$ \\
\hline Non- justified opinion & 29 & & $1.2 \%$ & 45 & & $1.5 \%$ \\
\hline Contextual questions & 309 & $12.8 \%$ & & 349 & $11.7 \%$ & \\
\hline New openings & 37 & & $1.5 \%$ & 31 & & $1.0 \%$ \\
\hline Technical & 13 & & $0.5 \%$ & 14 & & $0.5 \%$ \\
\hline Specifying & 158 & & $6.6 \%$ & 229 & & $7.7 \%$ \\
\hline Reasoning & 6 & & $0.2 \%$ & 8 & & $0.3 \%$ \\
\hline Opinion & 95 & & $4 \%$ & 67 & & $2.2 \%$ \\
\hline Shared problem solving & 520 & $21.6 \%$ & & 616 & $20.7 \%$ & \\
\hline Continues one's work & 152 & & $6.3 \%$ & 240 & & $8.1 \%$ \\
\hline Answers & 286 & & $11.9 \%$ & 315 & & $10.6 \%$ \\
\hline Disagrees / argues & 64 & & $2.7 \%$ & 47 & & $1.6 \%$ \\
\hline Reasons & 18 & & $0.7 \%$ & 14 & & $0.5 \%$ \\
\hline Management of interaction & 184 & $7.7 \%$ & & 157 & $5.3 \%$ & \\
\hline Group organization & 54 & & $2.2 \%$ & 59 & & $2.0 \%$ \\
\hline Planning upcoming activity & 19 & & $0.8 \%$ & 11 & & $0.4 \%$ \\
\hline Organizational questions & 109 & & $4.5 \%$ & 81 & & $2.7 \%$ \\
\hline Support & 2 & & & 6 & & \\
\hline $\begin{array}{l}\text { Summing-up } \\
\text { / discovering a solution }\end{array}$ & 71 & $3.0 \%$ & & 56 & $1.9 \%$ & \\
\hline Based on group activities & 59 & & $2.5 \%$ & 48 & & $1.6 \%$ \\
\hline Based on own actions & 2 & & $0.1 \%$ & 1 & & $0 \%$ \\
\hline Based on unknown reason & 10 & & $0.4 \%$ & 7 & & $0.2 \%$ \\
\hline Other input & 315 & $13,1 \%$ & & 1077 & $36,1 \%$ & \\
\hline
\end{tabular}




\begin{tabular}{|l|l|l|l|l|l|l|}
\hline Other input - related to task & 273 & & $11.4 \%$ & 477 & & $16 \%$ \\
\hline Describing technical problems & 7 & & $0.3 \%$ & 148 & & $5 \%$ \\
\hline Off task - Not related to task & 35 & & $1.5 \%$ & 452 & & $15.2 \%$ \\
\hline & $\begin{array}{l}2405 \\
\text { utterances }\end{array}$ & $100 \%$ & $100 \%$ & $\begin{array}{l}2981 \\
\text { utterances }\end{array}$ & $100 \%$ & $100 \%$ \\
\hline
\end{tabular}

The other main difference between studying with and without real-time teacher orchestration concerned the amount of other input, especially off-task talks. The participants in settings with teacher orchestration used 13 percent (315 utterances, of which 35 were off task) of their utterances for other input (for more detail, see Table 2 ), while the participants in setting without teacher orchestration used 36.1 percent (1077 utterances, of which 452 were off task) of their utterances (see Table 3). More specifically, the main problem in the setting without real-time teacher orchestration concerned the use of off-task discussions. Students studying without real-time orchestration seemed to become more easily distracted and discuss other topics when the same problems occurred, as can be seen in the following two examples (Examples 1 and 2). These two examples illustrate congruent phases of the problem-solving process that are created by having learners receive different information of the singers on the supporting group and headliners at the same time (on the needs of the bands and their equipment), but without proper coordination, causing an unsolvable problem (Moscovici \& Doise 1994; Cress \& Kimmerle 2008). In practice, team members receive complimentary and partly contradictory information regarding the bands (and singers) that they have to string together to resolve the socio-cognitive conflict. However, Example 2 also illustrates that as learners have developed (with the assistance of the teacher's orchestration) workable methods to maintain productive collaboration processes, the teacher's role is supportive (not channeling).

Example 1: Setting without real-time teacher orchestration and off topic discussions

Tom: Well they would hardly be brothers if he was a woman. (Shared problem solving; Reasoning)

Joel: Yep. (Shared problem solving; Agrees)

Tom: Mmm. (Other input; Related to task)

Tom: Then.. (Management of interaction; Group organization)

Tom: What about the drummer? (Management of interaction; Organizational question)

Jack: Er, long hair. (Shared problem solving; Answers)

Tom: Yes..and then? (Contextual questions; Specifying)

Tom: The drummer's stuff is there in the middle area. (Shared problem solving; Answers)

Tom: What else? (Contextual questions; Specifying)

Jack: Tell me! (Management of Interaction; Group organization)

Tom: Does anyone else have anything about the drummer? (Management of Interaction; Organizational question)

Jens: Well he's got a fair skin. (Shared problem solving; Answers)

Joel: No he hasn't. (Shared problem solving; Answers)

Sam: The drummer needs a microphone for singing. (Shared problem solving; Answers)

Tom: Ok. (Shared problem solving; Continue one's work)

Jack: Yeah. (Other input; Related to task)

Tom: So that is the drummer. Yes. (Summing-up; Based on group activities)

Tom: What about... the solo guitarist. Do you have anything about him?(Management of Interaction;

Organizational question)

Jens: Tow boxes.(Shared problem solving; Answers)

Jack: Does not like jewellery.(Shared problem solving; Answers)

Joel: On the right side of the singer while playing.(Shared problem solving; Answers)

Tom: So it's on this...no hell that can't be the solo guitarist (Summing-up; Based on group activities)

Jens: Who has messed with these? They are all [fucked up](Management of interaction; Organizational question)

Jens: There are three rythm guitarists here. (Providing knowledge; New information)

Tom: No, you see, I'm just changing them now. (Providing knowledge; Explaining one's own situation)

Tom: Don't mess with them now. (Providing knowledge; Piece of advice-contextual)

Jens: No I won't (Shared problem solving; Agrees)

Sam: Juho the monkey (Other input; Off task)

Joel: Ye...Unclear (Other input; Off task)

Jens: Er... (Other input; Off task) 
Sam: You're in such a stupid high pitch [pre-puberty "helium voice"] already (Other input; Off task)

Tom: What have we now...the drummer, the bassist and the solo guitarist were on the right side when playing. (Providing knowledge; New information)

Tom: Yes but it doesn't matter now at this point I think. (Providing knowledge; Non- justified opinion)

Tom: But...wait... (Providing knowledge; New information)

Tom: If that is...it can't be.. (Providing knowledge; New information)

Sam: Oh sh...(Other input; Off task)

Joel: What? (Other input; Off task)

Sam: What? (Other input; Off task)

Researcher's interpretation: Example 1 illustrates how students in the setting without real-time orchestration struggled to combine knowledge resources and focus on shared task solving when problems occurred. As students were discussing the problem that concerned the gender of the singers; Tom highlighted the fact that members of the band could not be brothers if the other was female (Shared problem solving; Reasoning). Joel agreed with that (Shared problem solving; Agrees), and Tom thought aloud (Other input; related to task), started to manage the group's work (Management of interaction; Group organization) and asked organizational questions of the drummer (Management of interaction; Organizational question). Jack answered with his piece of information (Shared problem solving; Answers) and Tom asked specifying questions (Contextual questions; Specifying). He did not get answers; therefore, he answered himself based on the knowledge he had (Shared problem solving; Answers) and asked again (Contextual questions; Specifying). As Tom still did not get any answers, Jack became nervous and commanded the others to share their knowledge (Management of interaction; Group organization). Then, Tom repeated his query (Management of interaction; Organizational question). Finally, Jens, Joel, and Sam answered with the information they had ( $X$ Shared problem solving; Answers). Tom continued trying to solve the problem concerning the gender and number of band members (Shared problem solving; Continue one's work) with the support of Jack (Other input; related to task). Then, Tom summarized what they knew based on Jens' and Sam's information (Summing-up; Based on group activities) and asked about the solo-guitarist (Management of interaction; Organizational question). He obtained answers from Jens, Jack, and Joel (3 X Shared problem solving; Answers). Then, Tom discovered a new incongruity and summed the situation up (Summing-up; Based on group activities). Jens inquired as to who had made exchanges without telling the others (Management of interaction; Organizational question), and noted that there were too many rhythm-guitarists (Providing knowledge; New information). Tom explained that he was merely making exchanges (Providing knowledge; Explaining own situation) and commented that Jens should leave them alone (Providing knowledge; Piece of advice - contextual). Jens agreed (Shared problem solving; Agrees). As they were not proceeding well, Sam, Joel, and Jens again contributed off task comments (Other input; Off task). As a consequence, Tom tried to return to the task (4 X Providing knowledge). However, Sam and Joel led the discussion off task again (3X Other input; Off task).

The above example illustrates the typical problem of how discussions can quickly move off topic (see also the amount of other talk in Table 3). As we can see, the nature of the exchanges between the students is goal-less, despite Tom's efforts to lead the problem solving process. However, the team does not have a clear, shared goal and intention to solve the specific problem as a team. We can see that, firstly, Tom had difficulty getting an answer from the others. In addition, the team seemed to make exchanges in the environment without informing the others, which causes confusion in the team environment. As solving the task was not proceeding well, the team strayed off topic in their communication. Alternatively, in the following Example 2, we will illustrate the same event with real-time teachers' orchestration. We will see that, although the teacher does not take the leading role, the team focuses more on reciprocal task solving and develops better ways to productively construct knowledge as the teacher's support is available to orchestrate complex learning processes if necessary, in contrast to Example 1.

Example 2: Setting with real-time teacher orchestration focusing on solving the problem set.

Ike: That...that singer is wrong (Providing knowledge; New information)

Rob: I don't know...it says here that the singer has got blue eyes. (Shared problem solving; Argues)

Ike: But it's a male singer (Shared problem solving; Argues)

Teacher: Ok then (Shared problem solving; Continue one's work) [1]

Rob: You just said that it's a woman (Shared problem solving; Disagrees)

Teacher: It says here that there's a female vocalist in the band. (Shared problem solving; Reasoning) [2]

Rob: Who says it? (Contextual questions; Specifying)

Björn: It says here that the singer and the bassist are brothers. (Shared problem solving; Reasoning)

Max: If there are two? (Summing-up; Based on group activities) 
Ike: There's just some discrepancy in this matter (Providing knowledge; Non- justified opinion)

Rob: My guess is that the singer is this (Providing knowledge; Non- justified opinion)

Rob: What if there are two singers? (Shared problem solving; Reasoning)

Ike: Yeah (Shared problem solving; Agrees)

Max: Well..let's say that those who have one box are singers. But...there..they both are chicks. Or is that a chic that other one? (Management of interaction; Organizational questions)

Björn: I don't know (Shared problem solving; Answers)

Ike: There is still a male vocalist in the band (Providing knowledge; New information)

Rob: Someone had a text where it said that there was a female singer too. (Shared problem solving; Argues)

Teacher: Yes, it says here that the band has a female singer (Shared problem solving; Continue one's work) [3]

Ike: But there are two female singers already. Two. (Shared problem solving; Disagrees)

Max: This is the singer who... (Summing-up; Based on group activities)

Max: The middle one...or whatever it is (Summing-up; Based on group activities)

Ike: Yes (Shared problem solving; Agrees)

Max: And then there are two of them. Which one of them it is then, of those chicks? (Summing-up; Based on group activities)

Ike: I don't know (Shared problem solving; Answers)

Rob: the guitar player and the bassist have both two of those boxes. And then that rhythm guitarist.. (Providing knowledge; New information)

Ike: It's the singer in that corner (Summing-up; Based on group activities)

Rob: If we only knew which ones of those they are (Summing-up; Based on group activities)

Max: So, we have now...hey, that singer, that..bloke in the middle there the outermost. (Summing-up; Based on group activities)

Rob: The singer has got one box. Don't you push those.. (Providing knowledge; New information)

Max: Well no, it's the male vocalist, he can play guitar while singing. (Shared problem solving; Reasoning)

Rob: Yes but there is a little discrepancy when it says there that the singer is a femaleand then it is a male.

(Shared problem solving; Disagrees/argues)

Max: Yes but there can be another one (Shared problem solving; Continue one's work)

Max: Because it says for some that... (Shared problem solving; Continue one's work)

Björn: But we already have a female singer. (Shared problem solving; Disagrees/argues)

Researcher's interpretation: In this example, the group realized that they had the wrong singer and Ike acknowledged this aloud (Providing knowledge; New information). Rob continued solving the problem by arguing about the singer (Shared problem solving; Argues) and Ike argued back (Shared problem solving; Argues). The teacher continued their discussion with comments supporting the group work (Shared problem solving; Continue one's work). Rob disagreed with the previous knowledge about the singer's gender (Shared problem solving; Disagrees) and the teacher provided a rationale based on the information provided by the environment (Shared problem solving; Reasoning). Thus, Rob tried to clarify who exactly knew (Contextual questions; Specifying) and Björn answered with his reasoning for the solution about the band members' gender (Shared problem solving; Reasoning). Max summarized the situation and presented a new point of view (Summing-up; Based on group activities). Ike highlighted that they had incongruity in their knowledge (Providing knowledge; Non- justified opinion) and Rob also gave his opinion on who could be the singer (Providing knowledge; Non- justified opinion). Then, Rob continued the shared problem solving by reasoning about the number of singers (Shared problem solving; Reasoning) and Ike agreed (Shared problem solving; Agrees). Max continued by determining what should they do (in a question form) (Management of interaction; Organizational questions). Björn responded (Shared problem solving; Answers). Ike provided new information about the singers (Providing knowledge; New information) and Rob argued against it (Shared problem solving; Argues). Then, the teacher repeated the existing information the group had gleaned from the environment (of the female singer) (Shared problem solving; Continue one's work) and Ike continued by pointing out the incongruity in the knowledge they had. Max continued by summarizing their knowledge of the singer ( $2 X$ Summing-up; Based on group activities) and Ike agreed (Shared problem solving; Agrees). Then, Max further summarized the knowledge (Summing-up; Based on group activities) and Ike responded (Shared problem solving; Answers). Then, Rob shared new information about the guitar and bass players (Providing knowledge; New information) and Ike, Rob, and Max continued by summing up the situation based on the group's work (3 $X$ Summing-up; Based on group activities). Next, Rob introduced new information about the deconstruction concerning the singer (Providing knowledge; New information). Finally, Max, Rob, and Björn continued to engage in shared problem solving by reasoning, arguing, and continuing the work.

From the above examples, we can see that this team clearly had a shared goal, there was no off-task discussion, and the nature of exchanges between team members was productive. As we can see, knowledge was clearly 
built on each other's ideas and thoughts. Furthermore, the group had several different means of encouraging one another (e.g. asking contextual questions, summing-up group activities, and stating agreements, disagreements, and reasons for different point of views). The above examples also reveal that the teacher did not take the authority or leading role in shared knowledge construction process. Instead, his activities are in the line with the notion that there is a need to emphasize the dialogue between all participants to enhance creative collaboration (Ruiz-Primo, Figueroa \& Gluckman, 2011). Example reveals typical way of teacher orchestration; as groups knowledge construction was on-topic and productive, the role of the teacher was to collaborate with students by continuing shared problem solving [1], [3] and reasoning [2]. The teacher's orchestration activities were grounded by intention to facilitate, channel, and monitor shared knowledge construction while he left the responsibility of solving the task to the students. Thus, in general the teacher's role as a fellow collaborator was to activate productive knowledge construction processes, such as encouraging students to formulate hypotheses, providing explanations, conceptualizing his own experiences, and describing observations (see also Hämäläinen and Vähäsantanen 2011). These two examples (1 and 2) shed light on how the setting with teacher orchestration used 13 percent ( 315 utterances, of which 35 were off task) of their utterances for other input, while groups without teacher orchestration used 36.1 percent (1077 utterances, of which 452 were off task) of their utterances. Thus, it is important to pay attention to the fact that real-time orchestration offered possibilities to enhance contextual interaction processes (e.g. support, questions, and perspectives from real-life experiences) and led to more productive knowledge construction than a lack of real-time teacher orchestration.

\section{Discussion and Conclusions}

Our earlier design-based studies have indicated that scripted learning environments have the potential to support high-level knowledge construction in vocational educational settings (Hämäläinen 2008, 2011; Hämäläinen et al. 2008). Thus, different kinds of collaboration scripts with theoretically-grounded design principles (e.g. arranging socio-cognitive conflicts) have been successfully used to foster specific interactions in technological environments. The CSCL research community has recently argued that there is an excessive focus on specific technological environments, as research has typically focused on developing learning environments that would replace the teacher rather than position him/her at the center (Kollar et al. 2011). Therefore, this study shifts the focus also to the relation between pedagogical scenarios, collaborative learning, and teachers' real-time activities. It can be argued that, in virtual settings, collaboration is related to pedagogical design and teachers' timely support for collaborative knowledge construction. Similarly, research needs to supplement developing the environments themselves with a focus on teachers' flexible ways of orchestrating learning in future TEL settings and virtual spaces (see Dillenbourg \& Jermann 2010). In the current state, there seems to be a lack of studies focusing on the role of the teacher as an external orchestrator or fellow collaborator orchestrating knowledge construction processes "on the fly" within 3D spaces. Therefore, this study is one attempt to fill in this knowledge gap. The study is grounded on the notion that the teacher is as an important actor in productive collaboration processes (Tharp, et al. 2000). Thus, our aim is to provide new insight into what actually happens in collaboration processes within different learning settings, which can then be applied to help teachers to make their decisions regarding how to fully apply $3 \mathrm{D}$ games in their teaching.

This study attempts to carry design experimentation into an authentic educational setting to determine what works in practice. However, this means giving up a psychological research tradition in which results are based on the notion of controlling variables (Collins 1999). Thus, we have to accept the limitation that our approach makes it impossible to control the influence of single parameters, and therefore, the results of this study can only lead to exploratory level knowledge (see also Herrmann \& Kienle 2008). Moreover, according to Oh and Reevers (2010), design research has more pragmatic goals than traditional educational research, as the goal is to design innovative interventions to solve problems in educational practice. Nevertheless, our findings have several limitations. First, our study lacked individual perspectives on the learning process (as the main focus is on the differences in knowledge construction processes between learning settings). Second, only the short-term impact on knowledge construction was evaluated using content analysis. Third, since our research was informed by a socio-cultural perspective and the teacher was seen as an important actor in productive collaboration processes, it was not possible to evaluate different interactions, only students' knowledge construction processes. Fourth, the empirical study was designed for a particular learning context and for a small number of subjects. Therefore, the findings are not widely generalizable (Shavelson, Phillips, Towne \& Feuer 2003). However, one strength of this study is that, along with the development of learning environments, it pays attention to the effective and flexible use of the potential offered by future 3D learning spaces with regard to the teacher's more active role as an orchestrator and fellow collaborator of the productive knowledge construction processes, which has rarely been explored to date.

Our findings indicated that groups studying with real-time teacher orchestration exerted more effort to provide knowledge (particularly when explaining one's own situation) and less effort for other input (especially off-task 
talk). Thus, the scripted 3D game itself gave guidance and help in task solving. However, the teacher's professional competencies (e.g. Brühwiler \& Blatchford 2011) were particularly helpful for reducing off-task discussions in the 3D game, developing a shared understanding of the inter-professional nature of the task, and explaining one's own activities in a meaningful way as a part of solving inter-professional tasks. As demonstrated in Example 2, problem solving in settings with teacher's real-time orchestration can be called productive knowledge construction, as members develop processes of shared knowledge construction built on others' ideas and thoughts (see also Arvaja et al. 2007). In contrast, despite the support of the scripted environment, students were not able to develop ways of explaining their own situation to lead to productive knowledge construction processes without the teacher's assistance (see Example 1). Thus, the teacher seems to play special role in enhancing such processes in the scripted 3D settings, as teachers were able to develop "on the fly" (see also Dillenbourg \& Jermann 2010) different ways of fostering these processes within the group (e.g., by asking questions and highlighting real-life scenarios). This suggests the potential of real-time teacher orchestration in vocational 3D learning settings (in particular, explaining one's own situation) to be highly related to inter-professional work, and practicing that is one way to respond to the changing needs of people's future work lives. As such, future research is needed on the relation of teachers' role in assisting groups to regulate and empower group processes. We also need to seek the potentials of studies in socially constructed self-regulated learning (e.g. Järvelä \& Järvenoja 2011) and further investigate the role of the teachers' real-time orchestrator of these processes.

To conclude, real-time orchestration seems to have the potential to improve knowledge construction processes in scripted 3D environments. The orchestrated learning setting was not only faster, but also had more knowledge construction processes that can be considered productive. This highlights the role of the teacher in enhancing productive collaboration. At their best, technological environments can support teachers' abilities to foster productive knowledge construction by offering new functional and sociable (see Kreijins et al. 2007) learning spaces for knowledge construction and helping teachers to orchestrate and monitor learning activities. However, enhancing productive knowledge construction processes is a challenging task. Wegerif (2006) has even argued that, at the current stage, some of the underlying assumptions behind CSCL pedagogies are mainly based on the industrial age and focus too much on individual knowledge and skills. Therefore, to support collaboration in naturalistic learning contexts, teachers need to develop new working methods. This study is based on the notion that the teacher's role in orchestrating learning is not only as the facilitator, but also as a fellow contributor, joining the students in collaboration processes. As we can see from Example 2, the role of the teacher did not seem to be "traditional knowledge recourse" for individual learners; rather, he encouraged group work by taking advantage of the contextual resources (see Arvaja 2011) of the students and real-life work situations (Billett 2008). The findings support the argument of Dillenbourg and Jermann (2010) that there is a need to put the teacher back in the center of learning processes. However, for effective $21^{\text {st }}$-century education, putting the teacher back in the center does not mean traditional "teacher centrism." Instead, to meet the needs of the future TEL, the role of the teacher needs to highlight teachers' possibilities to orchestrate learning and empower knowledge construction processes. In practice this can mean, for example, teachers' external support for collaborative learning (Kollar, Wecker, Langer \& Fischer 2011), or facilitating learning through joint construction of knowledge in which teachers and students work together on a common product and goal (Mercer, Hennessy \& Warwick 2010).

In this study, teachers' role as fellow collaborators was to activate productive knowledge construction processes, for example by encouraging students to formulate hypotheses, provide explanations, conceptualize their own experiences, and describe what was happening in the problem-solving context (see also Hämäläinen \& Vähäsantanen 2011). Our next study will focus on how teachers actually support productive knowledge contraction in scripted 3D settings and how, for example leadership, flexibility, control, integration, linearity, continuity, and drama are applied in teachers' orchestration activities (see Dillenbourg \& Jermann 2010). Furthermore, additional research on the support of collaborative learning with both technology and human guidance (see Azevedo et al. 2008) is needed in order to develop efficient pedagogical approaches to truly meet the needs of CSCL in naturalistic learning contexts. In the future, orchestrating learning must be both pedagogically structured (based on learning theories) and also flexible to achieve learning goals. Thus, the learning goal (and task involved in attaining the goal) and contextual needs set the limits for how much learning should be designed, instructed, and orchestrated.

Acknowledgements

This research was supported by the Academy of Finland (Project 258659). The development of the 3D environment was supported by the EU Structural Funds and nationally by the State Provincial Office of Western Finland from the administrative sector of the Ministry of Education. 


\section{References}

Arvaja, M. (2007). Contextual perspective in analysing collaborative knowledge construction of two small groups in web-based discussion. International Journal of Computer-Supported Collaborative Learning, 2(2/3), 133-158.

Arvaja, M. (2011). Analyzing the contextual nature of collaborative activity. In S. Puntambekar, G. Erkens \& C. Hmelo-Silver (Eds.), Analyzing interactions in CSCL: methods, approaches and issues (pp. 25-46). Computer-Supported Collaborative Learning Series, Vol 12. NY: Springer.

Arvaja, M., Salovaara, H., Häkkinen, P., \& Järvelä, S. (2007). Combining individual and group-level perspectives for studying collaborative knowledge construction in context. Learning and Instruction, 17(4), 448-459.

Arvaja, M., Hämäläinen, R., \& Rasku-Puttonen, H. (2009). Challenges for the teacher's role in promoting productive knowledge construction in computer-supported collaborative learning contexts. In J. O. Lindberg \& A. D. Olofsson, Online learning communities and teacher professional development: Methods for improved education delivery (pp. 263-280). Hersey: IGI Global,.

Azevedo, R., Moos, D.C., Greene, J.A., Winters, F.I., \& Crornley, J.G. (2008). Why is externally-facilitated regulated learning more effective than self-regulated learning with hypermedia? Educational Technology Research and Development, 56(1), 45-72.

Baker, M. (2010, September). Approaches to understanding students' dialogues: articulating multiple modes of interaction. Keynote speaker lecture presented to an EARLI SIG 17 "Qualitative and Quantitative Approaches to Learning and Instruction”. Jena, Germany.

Barab, S.A., \& Squire, K. (2004). Design-based research: putting a stake in the ground. The Journal of the Learning Sciences, 13(1), 1-14.

Barron, B. (2000). Achieving coordination in collaborative problem solving groups. The Journal of the Learning Sciences, 9(4), 403-436.

Beers, P.J., Boshuizen, H.P.A., Kirschner, P.A., \& Gijselaers, W.H. (2007). The analysis of negotiation of common ground in CSCL. Learning \& Instruction, 17(4), 427-435.

Berger, C.R., \& Calabrese, R.J. (1975). Some explorations in initial interaction and beyond: toward a developmental theory of interpersonal communication. Human Communication Research, 1(2), 99112.

Berelson, B. (1952). Content analysis in communication research. Glencoe, IL: Free Press.

Billett, S. (2008). The workplace as learning environment: introduction. International Journal of Educational Research, 47 (4), 209-212.

Bouta, H. Retalis, S. \& Paraskeva F. (2012). Utilizing a collaborative macro-script to enhance student engagement: A mixed method study in a 3D virtual environment. Computers \& Education, 58(1), 501517.

Brown, A. (1992). Design experiments: theoretical and methodological challenges in creating complex interventions in classroom settings. The Journal of Learning Sciences, 2(2), 141-178.

Brown, A. \& Campione, J. (1994). Guided discovery in a community of learners. In K. McGilly, Classroom lessons: integrating cognitive theory and classroom practice (pp. 227-270). Cambridge, MA: MIT Press.

Brühwiler, C. \& Blatchford, P. (2011). Effects of class size and adaptive teaching competency on classroom processes and academic outcome. Learning and Instruction. 21(1), 95-108.

Collazos, C., Guerrero, L., Pino, J., \& Ochoa, S. (2003). Collaborative scenarios to promote positive interdependence among group members. Lecture Notes in Computer Science, 2806, 356-370.

Chi, M. (1997). Quantifying qualitative analysis of verbal data: a practical guide. Journal of the Learning Sciences, 6(3), 271-315.

Clark, V.L, Creswell, J.W., Green, D.O., \& Shope, R.J. (2008). Mixing quantitative and qualitative approaches: an introduction to emergent mixed methods research. In S.N. Hess-Biber \& P. Leavy, Handbook of emergent methods (pp. 363-387). New York: Guilford.

Collazos, C., Guerrero, L., Pino, J., \& Ochoa, S. (2003). Collaborative scenarios to promote positive interdependence among group members. Lecture Notes in Computer Science, 2806, 356-370.

Collin, K., Paloniemi, S., \& Mecklin, J-P. (2010). Promoting inter-professional teamwork and learning - the case of a surgical operating theatre. Journal of Education and Work, 23(1), 43-63.

Collins, A. (1999). The changing infrastructure of education research. In E. C. Lagemann \& L. S. Shulman, Issues in education research: problems and possibilities (pp. 289-298). San Francisco: Jossey-Bass.

Cress, U., \& Kimmerle, J. (2008). A systemic and cognitive view on collaborative knowledge building with wikis. International Journal of Computer-Supported Collaborative Learning, 3, 105-122.

Crook, C. (1998). Children as computer users: the case of collaborative learning. Computers and Education, 30, 237-247. 
Design-Based Research Collective. (2003). Design-based research: an emerging paradigm for educational inquiry. Educational Researcher, 32(1), 5-8.

De Wever, B., Schellens, T., Valcke, M., \& Van Keer, H. (2006). Content analysis schemes to analyze transcripts of online asynchronous discussion groups: a review. Computers \& Education, 46 (1), 6-28.

De Wever, B., Van Keer, H., Schellens, T., \& Valcke, M. (2010). Structuring asynchronous discussion groups: comparing scripting by assigning roles with regulation by cross-age peer tutors. Learning and Instruction, 20(5), 349-360.

Dillenbourg, P. (2006). The solo/duo gap. Computers in Human Behavior, 22 (1), 155-159.

Dillenbourg, P., \& Jermann, P. (2010). Technology for classroom orchestration. In M.S. Khine and I.M. Saleh, New science of learning. Springer Science+Business Media, New York, 525-552.

Dillenbourg P., Järvelä S., \& Fischer F. (2009). The evolution of research on computer-supported collaborative learning: from design to orchestration. In Balacheff, N., Ludvigsen, S., de Jong, T., Lazonder, T.A. \& S. Barnes, Technology enhanced learning: principles and products. Springer, Netherlands, 3-19.

Dillenbourg, P., \& Tchounikine, P. (2007). Flexibility in macro-scripts for computer-supported collaborative learning. Journal of Computer Assisted Learning, 23(1), 1-13.

Eteläpelto, A., \& Lahti, J. (2008). The resources and obstacles of creative collaboration in long-term learning community. Thinking Skills and Creativity, 3(3), 226-240.

Glăveanu, V.P. (2010). Paradigms in the study of creativity: introducing the perspective of cultural psychology. New Ideas in Psychology, 28(1), 79-93.

Hadwin, A. \& Järvelä, S. (2011). Social aspects of self-regulated learning: where social and self meet in the strategic regulation of learning. Teachers College Records, 113(2), 235-239.

Hämäläinen, R. (2008). Designing and evaluating collaboration in a virtual game environment for vocational learning. Computers \& Education, 50(1), (98-109).

Hämäläinen, R. (2011). Using a game environment to foster collaborative learning: a design-based study. Technology, Pedagogy and Education, 20(1), 45-62.

Hämäläinen, R., \& Häkkinen, P. (2010). Teachers' instructional planning for computer-supported collaborative learning: macro-scripts as a pedagogical method to facilitate collaborative learning. Teaching and Teacher Education, 26(4), 871-877.

Hämäläinen, R., Oksanen, K., \& Häkkinen, P. (2008). Designing and analyzing collaboration in a scripted game for vocational education. Computers in Human Behavior, 24(6), 2496-2506.

Hämäläinen, R., \& Vähäsantanen, K. (2011). Theoretical and pedagogical perspectives on orchestrating creativity and collaborative learning. Educational Research Review. 6(3), 169-184.

Herrmann, T., \& Kienle, A. (2008), Context-oriented communication and the design of computer supported discursive learning, Computer Support for Collaborative Learning, 3(3).

Hesse-Biber, S N. (2010). Mixed methods research: merging theory with practice. New York: Guilford.

Hmelo-Silver, C.E. (2003). Analyzing collaborative knowledge construction multiple methods for integrated understanding. Computers \& Education, 41(4), 397-420.

Hoadley, C. (2004). Methodological alignment in design-based research. Educational Psychologist, 39(4), 203212.

Howe, C., \& Tolmie, A. (1999). Productive interaction in the context of computer-supported collaborative learning in science. In K. Littleton, Learning with computers: analyzing productive interaction (pp. 24-45). New York: Routledge.

Jeong, H., \& Hmelo-Silver, C.E. (2010). Productive use of learning resources in an online problem-based learning environment, Computers in Human Behavior, 26(1), 84-99.

John-Steiner, V. (2000). Creative collaboration. Oxford: Oxford University Press.

Järvelä, S. \& Järvenoja, H. (2011). Socially constructed self-regulated learning in collaborative learning groups. Teachers College Records, 113(2), 350-374.

Järvelä, S., Volet, S., \& Järvenoja, H. (2010). Research on motivation in collaborative learning: moving beyond the cognitive-situative divide and combining individual and social processes. Educational Psychologist, 45 (1), 15-27.

Kreijns, K., Kirschner, P. A., Jochems, W., \& Buuren, H. V. (2007) Measuring perceived sociability of computer-supported collaborative learning environments. Computers \& Education, 49(2), 176-192.

Kobbe L., Weinberger A., Dillenbourg P., Harrer A., Hämäläinen R., Häkkinen P., et al. (2007). Specifying computer-supported collaboration scripts. International Journal of Computer-Supported Collaborative Learning, 2(2/3), 211-224.

Kollar, I., Fischer, F., \& Slotta, J.D. (2007). Internal and external scripts in computer-supported collaborative inquiry learning. learning and instruction, 17(6), 708-721.

Kollar, I., Hämäläinen, R., Evans, M., De Wever, B., \& Perrotta, C. (2011). Orchestrating CSCL - more than a metaphor? In H. Spada, G. Stahl, N. Miyake, \&, N. Law, Connecting computer-supported 
collaborative learning to policy and practice: CSCL2011 conference proceedings. Volume II. (pp. 946-947). International Society of the Learning Sciences.

Kollar, I., Wecker, C., Langer, S. \& Fischer, F. (2011). Orchestrating web-based collaborative inquiry learning with small group and classroom scripts. In H. Spada, G. Stahl, N. Miyake, \&, N. Law, Connecting computer-supported collaborative learning to policy and practice: CSCL2011 conference proceedings. Volume I - Long papers (pp. 422-429). International Society of the Learning Sciences.

Kollar, I. (2010). Turning the classroom of the future into the classroom of the present. In K. Mäkitalo-Siegl, J. Zottmann, F. Kaplan \& F. Fischer, The classroom of the future: orchestrating collaborative learning spaces (pp. 245-255). Rotterdam: Sense.

Littleton, K. (2009, August). Communication, collaboration and creativity: How musicians negotiate a collective 'sound', paper presented to a symposium conducted at the $13^{\text {th }}$ biennial EARLI conference, the Netherlands.

Lund, A. \& Rasmussen, I. (2008). The right tool for the wrong task? Match and mismatch between first and second stimulus in double stimulation. International Journal of Computer-Supported Collaborative Learning, 3(4), 387-412.

Lund, A. \& Smørdal, O. (2006). Is there a space for the teacher in a Wiki? Paper presented at The 2006 International Symposium on Wikis, August 21-23, 2006, Odense, Denmark. Retrieved August 19, 2011 from http://portal.acm.org/citation.cfm?id=1149466

Meyer, J. H. F. \& Watson, R.M. (1991). Evaluating the quality of student learning. II - study orchestration and the curriculum. Studies in Higher Education, 16, 251-275.

Mercer, N. (1996). The quality of talk in children's collaborative activity in classroom. Learning and Instruction, 6(4), 359-377.

Mercer, N. (2010). The analysis of classroom talk: methods and methodologies. The British Journal of Educational Psychology,80, 1-14.

Miell, D. \& Littleton, K. (2004). Collaborative creativity: contemporary perspectives. London: Free Association Books.

Mercer, N. Hennessy, S., \& Warwick, P. (2010). Using interactive whiteboards to orchestrate classroom dialogue, Technology, Pedagogy and Education, 19(2), 195-209.

Moscovici, S., \& Doise, W. (1994). Conflict and consensus: a general theory of collective decisions. London: Sage Publications.

Oh, E., \& Reeves, C., (2010). The implications of the differences between design research and instructional systems design for educational technology researchers and practitioners, 47(4), 263-275.

Pea, R.D. (2004). The social and technological dimensions of scaffolding and related theoretical concepts for learning, education, and human activity. Journal of the Learning Sciences, 13(3), 423-451.

Price, S., Rogers, Y., Stanton, D., \& Smith, H. (2003). A new conceptual framework for CSCL: supporting diverse forms of reflection through multiple interactions. In B. Wasson, S. Ludvigsen, U. Hoppe, Designing for change in networked learning environments. Proceedings of the International Conference on Computer Support for Collaborative Learning. (pp. 513 - 523). Bergen: InterMedia.

Ravenscroft, A., Sagar, M., Baur, E., \& Oriogun, P. (2008). Ambient pedagogies, meaningful learning and social software. In S. Hatzipanagos \& S. Warburton, Social software \& developing community ontologies (pp. 432-450). Hershey: IGI Global.

Roschelle, J. \& Teasley, S. (1995). The construction of shared knowledge in collaborative problem solving. In C. O’Malley, Computer supported collaborative learning (pp. 69-97). NATO ASO Series F: Computer and System Sciences, Vol. 128. Berlin: Springer-Verlag.

Ruiz-Primo, M.A., Figueroa, M., \& Gluckman, M. (2011). Testing a premise of inquiry based science instruction: exploring small group processes and its link to student learning. Paper presented at the AERA meeting, April 2011.

Shavelson, R.J., Phillips, D.C., Towne, L., \& Feuer, M.J. (2003). On the science of education design studies. Educational Researcher, 32(1), 25-28.

Sawyer, R.K. (2004). Creative teaching: collaborative discussion as disciplined improvisation. Educational Researcher, 33(3), 12-20.

Sawyer, R.K. (2006). Educating for innovation. Thinking Skills and Creativity, 1(1), 41-48.

Sawyer, R.K. (2007). Group genius: the creative power of collaboration. New York: Basic Books.

Sawyer, R.K., \& DeZutter, S. (2009). Distributed creativity: how collective creations emerge from collaboration. Journal of Aesthetics, Creativity, and the Arts, 3(2), 81-92.

Stahl, G. (2004). Building collaborative knowing. elements of a social theory of CSCL. In P. Dillenbourg, J. W. Strijbos, P. A. Kirschner \& R. L. Martens, Computer-supported collaborative learning, Vol. 3. What we know about CSCL... and implementing it in higher education. (pp. 53-85). Boston, MA: Kluwer Academic Publishers. 
Stahl, G. (2006). Group cognition: computer support for building collaborative knowledge. Cambridge, MA: MIT Press. Retrieved 29.6.2011. http://www.cis.drexel.edu/faculty/gerry/mit/

Strijbos, J.W. \& De Laat, M.F. (2010). Developing the role concept for computer-supported collaborative learning: An explorative synthesis. Computers in Human Behavior, 26, 495-505.

Tchounikine, P. (2008). Operationalizing macro-scripts in CSCL technological settings. International Journal of Computer-Supported Collaborative Learning, 3(2), 193-233.

Tharp, R.G., Estrada, P., Dalton, S.S. \& Yamauchi, L.A. (2000). Teaching transformed. achieving excellence, fairness, inclusion, and harmony. Boulder, CO: Westview Press.

Wang, Q. (2009). Design and evaluation of a collaborative learning environment. Computers and Education 53(4), 1138-1146.

Wang, F., \& Hannafin, M. J. (2005). Design-based research and technology-enhanced learning environments. Educational Technology Research and Development, 53(4), 5-23.

Wegerif, R. (2007). Dialogic education and technology. New York: Springer Verlag.

Wegerif, R. (2006). A dialogical understanding of the relationship between CSCL and teaching thinking skills. International Journal of Computer-Supported Collaborative Learning (ijCSCL), 1(1), 143-157.

Wells, G. \& Claxton, G. (2002). Introduction: sociocultural perspectives on the future of education. In G. Wells, \& G. Claxton, Learning for life in the 21st century: sociocultural perspectives on the future of education (pp. 1-18). Oxford: Blackwell.

Vosniadou, S.I., Ioannides, C., Dimitrakopoulou, A., \& Papademetriou, E. (2001). Designing learning environments to promote conceptual change in science. Learning and Instruction, 11(4), 281-419.

Vygotsky, L. (1978). Mind and society. Cambridge, MA: Harvard University Press. 